\title{
Khat Chewing Induces Cardiac Arrhythmia
}

\author{
Dhaifullah Jayed, Mohamed Ali Al-Huthi \\ Department of Internal Medicine, Faculty of Medicine, Thamar University, Thamar City, Yemen \\ Email: dhaifullahj@yahoo.com
}

Received 8 June 2016; accepted 23 July 2016; published 26 July 2016

Copyright (C) 2016 by authors and OALib.

This work is licensed under the Creative Commons Attribution International License (CC BY).

http://creativecommons.org/licenses/by/4.0/

(c) (i) Open Access

\begin{abstract}
Background: Khat is a natural stimulant from the Catha edulis plant containing several chemical components, which can explain palpitation as a frequent symptom that develops during or after khat chewing. Aims: To study the effects of khat chewing on cardiac rhythm. Methods: We selected sixty khat-chewing Yemeni individuals and divided them into two groups: 30 were cardiac patients and the other 30 were non-cardiac individuals. All 60 individuals underwent 24 hours holter monitoring for 2 consequent days; the first was a khat-free day and the next was a khat-chewing day. The two groups were matched for age, sex, smoking habit, BSA, systolic and diastolic blood pressure. Non sustained Ventricular Tachycardia (VT) was defined as 3 or more wide QRS complexes at a rate of 120 beats/min and for a period less than 20 seconds. Results: The non-sustained VT was found on $7(23.3 \%)$ of the 30 cardiac patients on a khat-chewing day compared to 2 patients $(6.6 \%)$ on a khat-free day $(p<0.01)$. A significant difference was also seen among the normal individuals; 1 patient (3.3\%) developed short runs of VT on a khat-chewing day compared to non VT on a khat-free day. Conclusions: 1) Serious arrhythmias occur in both cardiac and noncardiac individuals during khat chewing days although they are more prominent among cardiac patients. 2) This may indicate beta-blocker usage for high risk khat chewers before khat chewing.
\end{abstract}

\section{Keywords}

Khat, Ventricular Tachycardia, Echocardiography, Holter Monitoring, Arrhythmia

Subject Areas: Internal Medicine

\section{Introduction}

Khat or Catha edulis is an indigenous plant in Yemen, Ethiopia and East Africa, which has sympathomimetic and euphoriant effects. It is chewed habitually by people for its pleasurable effect and it produces stimulant amphetamine-like effects that are attributable to Cathinone, a phenylethylamine which is present in fresh leaves [1].

Khat contains a complex group of alkaloids (includes Cathinone, Cathine, Ephedrine, and many others) [2]. It also contains glycoside such as Ampelopsin, Tannins, Choline, inorganic salts such as calcium and iron, and vitamins such as vitamin $\mathrm{C}$ and amino acids [2] [3]. 
Khat chewing has been associated with clinical psychiatric morbidity [4]-[6], and implicated in induction of alteration in the serotonin [7]. Recently, it was documented that Cathinone acted as well on noradrenaline transporters [8]. Therefore, at this juncture, other mechanisms which have not been discovered yet could not be excluded in the pharmacological action of Cathedulates or Chathinone.

Khat's strongly-astringent tannins may lead to gastritis, stomatitis, oesophagitis and periodontal diseases. The produced Tannic acids are also thought to be Hepatotoxic. Cathinone is currently believed to be the main active ingredient in fresh khat leaves.

The cardiovascular changes, induced by chewing khat, show evidence of a significant rise in arterial systolic and diastolic blood pressure and pulse rate with a peak effect of three hours after starting chewing khat. These changes run parallel with the changes in plasma Cathinone levels during and after khat chewing [9].

Studies on rats and monkeys have shown that its central system effects are similar in some ways to those of D-amphetamines and in other ways to those of Cocaine. Thus, Cathinone has been found to be a central nervous system stimulant which increases heart rate, locomotor activity, and oxygen consumption [10].

Clinically, it has been noted that palpitations, chest discomfort, and even sudden death are not uncommon during and post khat chewing. This has been confirmed by several clinical studies, which find that khat chewing carries a potential cardiovascular risk particularly in patients with hypertension and heart disease, and might precipitate the occurrence of cerebrovascular accidents (stroke) and myocardial infarction (heart attack) in susceptible individuals [11]. Thus, our present study has been designed to evaluate the role of khat chewing in inducing cardiac arrhythmias, particularly in ventricular arrhythmia.

Purpose of Study

- To study the effects of khat chewing on cardiac rhythm.

- To determine the necessity for susceptible individuals of cardiovascular risk to use beta-blocker before khat chewing.

\section{Methods}

\subsection{Population}

A population consists of 60 male and female individuals ranging in age from 30 - 60 years old are divided into two groups, each of which contains 30 individuals: the first group comprises 30 cardiac patients of mild and moderate cardiac symptoms but advanced stage, emergency and life threatening cardiac patient were excluded, and the second group also comprises 30 normal individuals. The selected individuals were attending inpatient and outpatient clinics at Kuwait University Teaching Hospital-Sana'a.

The study was approved by the local scientific ethics committee, the included individuals were informed about the study and asked for their participation, taking the consent of those who agreed to be included in this study.

\subsection{Study Design}

The selected cardiac and/or hypertensive patients underwent an electrocardiography, chest X-ray, echocardiography, followed by an ambulatory 24-hour ECG holter monitoring which was applied for two consecutive days: the first day was a khat-free day and the next was a khat-chewing day.

\subsection{Blood Pressure (BP)}

After at least 5 minutes of rest in a sitting position, BP was measured for all patients for bilateral arms using sphygmomanometer with the appropriate cuff size. Three measurements were taken at least 5 minutes apart and the mean BP was used for analysis.

\subsection{Body Surface Area (BSA)}

Body Surface Area was calculated by square root of product of the weight (in $\mathrm{kg}$ ) and the height (in $\mathrm{cm}$ ) divided by 3600 .

\subsection{Electrocardiogram}

Standard 12-lead electrocardiogram recorded with a paper speed of $25 \mathrm{~mm}$ per second and standardization of 1 
mv per centimeter by Cardimax; an electrocardiographic machine, model FX-7302, made in Japan by Fukuda Corporation.

\subsection{Echocardiography}

It was carried out by one investigator, using GE Vingmed Vivid 7 Computed Sonography, with an adult cardiac transducer 3S 1.5/3.6 MHz frequency and an aperture size of $19 \mathrm{~mm}$. M-mode record, which was guided by two dimensional views, recorded into 6 inch paper with a paper speed of $50 \mathrm{~mm}$ per second.

Left ventricular posterior wall thickness, interventricular septal thickness, and left ventricular end diastolic and systolic diameters were all measured at the distal to the tips of mitral valve leaflets and at the peak of $\mathrm{R}$-wave on the electrocardiogram.

Measurements were made over three consecutive cardiac cycles, taking into consideration the calculated mean values. Moreover, any detected cardiac abnormality was labeled and included in its group.

\subsection{Ambulatory Electrocardiographic Monitoring}

It is also called holter monitoring. 24-hour holter ambulatory electrocardiographic monitoring was conducted with the use of Kenz Cardy Holter Analysis system model 302 with standard CC5 and CM5 lead. The complete 24-hour recording was printed with a full disclosure unit and, then, analyzed by two investigators. Recordings were done in two days separately: the first was on a khat-free day and the second was on a khat-chewing day.

\subsection{Statistical Analysis}

The parametric data such as age, BSA, blood pressure and echocardiographic parameters were expressed as mean + SEM. Statistical analysis of the data was carried out using the statistical package for social sciences (SPSS Software Package). Differences between the two groups were analyzed with a two-tailed test. The result was analyzed using students (unpaired) test of significance for continuous variable and persons Chi-square test for categorical data (comparing proportion). Odds ratio (OR) with 95\% confidence interval (CI) was calculated from $2 * 2$ table to assess the degree of association. Significance was taken as less than 0.05 .

\section{Results}

\subsection{Clinical Characteristics}

As in Table 1, there were no statistical significant differences between the two groups regarding age, height, weight, BSA, systolic and diastolic blood pressure, but significant differences were detected between the two groups in 24-hour ambulatory ECG monitoring findings.

\subsection{Ambulatory E.C.G Monitoring}

Ventricular extrasystoles were more common on a khat-chewing day than on a khat-free day for all individuals, as in Figure 1 and Table 2. However, they were significantly more common among cardiac patients than normal individuals both on khat-chewing and khat-free days (Figure 2 and Figure 3).

Table 1. Characteristics of cardiac and normal groups.

\begin{tabular}{ccc}
\hline Demographic Features & Cardiac Group (N = 30) & Normal Group (N = 30) \\
Age (yr) & $47 \pm 8$ & $46 \pm 9$ \\
Height (cm) & $164 \pm 8$ & $163 \pm 9$ \\
Weight (kg) & $67 \pm 3$ & $13 \%$ \\
Smokers & $13 \%$ & $112 \pm 6$ \\
Blood Pressure (mmHg) & $115 \pm 5$ & $78 \pm 6$ \\
Systolic BP & $80 \pm 8$ \\
Diastolic BP & & \\
\hline
\end{tabular}




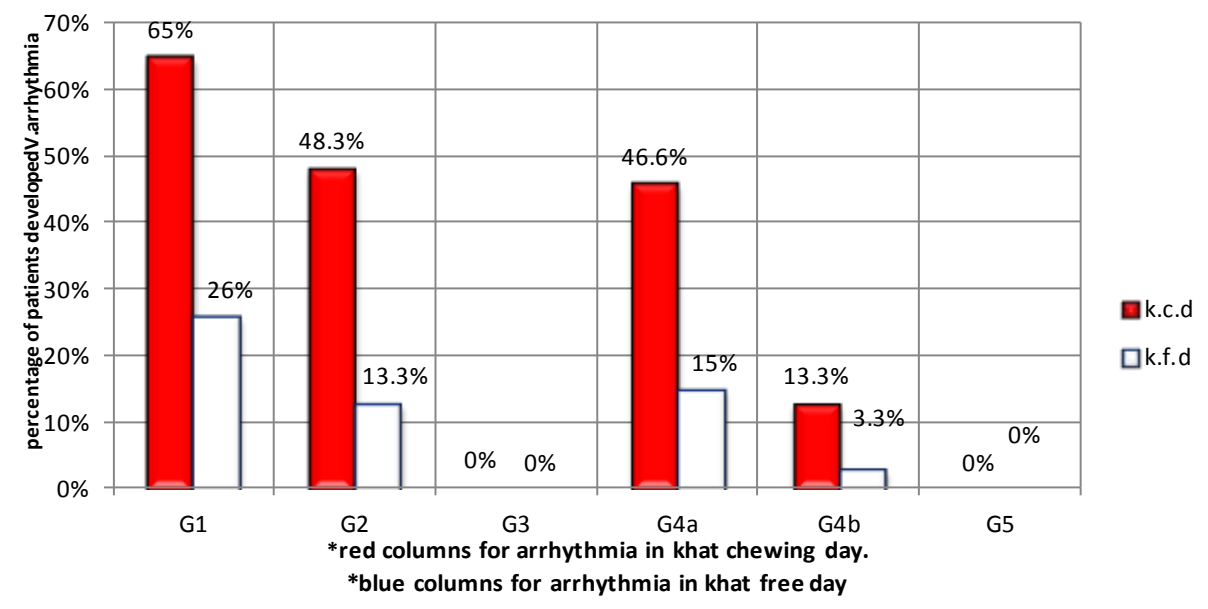

Figure 1. Grading of arrhythmia in all population (according to lown's classification). k.c.d = khat chewing day, k.f.d = khat free day , $G$ = grade.

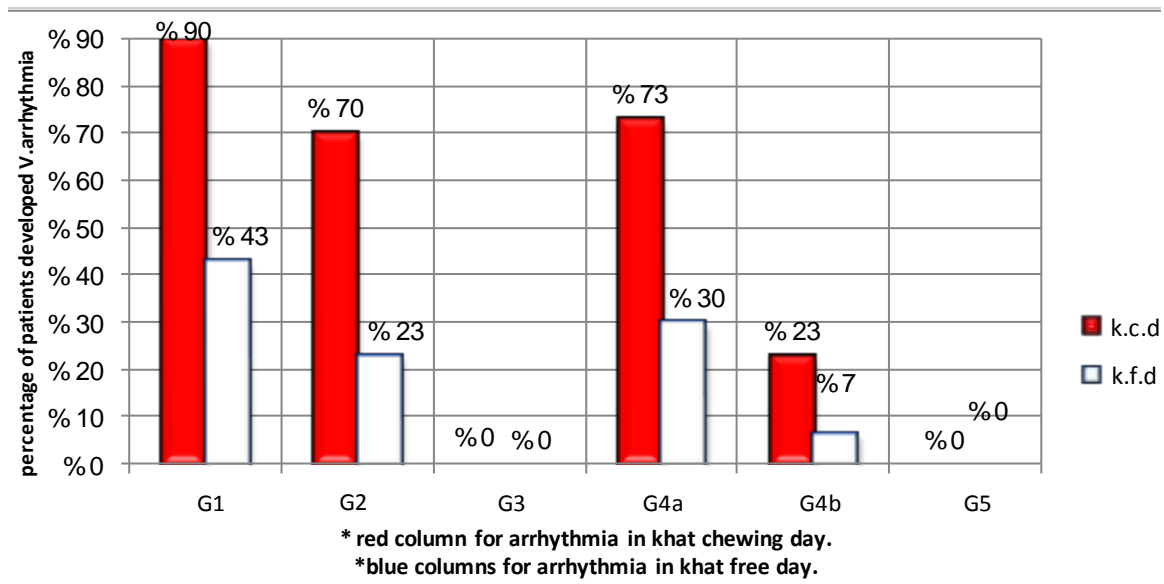

Figure 2. Prevalence of ventricular arrhythmia (according to lown's classification) among cardiac patients in khat chewing and khat free days. k.c.d = khat chewing day, k.f.d = khat free day , $\mathrm{G}=$ grade.

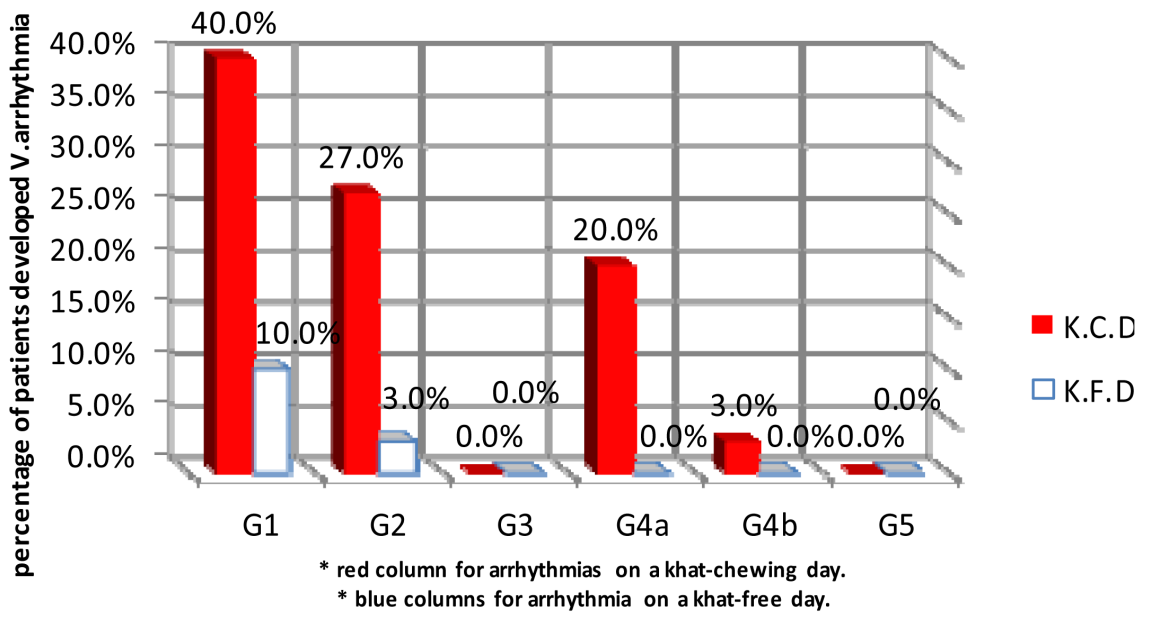

Figure 3. Prevalence of ventricular arrhythmia among normal individuals on a khat-chewing and khat-free days. k.c.d = khat chewing day, k.f.d = khat free day, $\mathrm{G}=$ grade. 
Table 2. Prevalence of simple and complex ventricular arrhythmias on khat-chewing and khat-free days among whole population.

\begin{tabular}{cccc}
\hline Ventricular Arrhythmia & Khat-Chewing Days (No=60) & Khat-Free Days (No= 60) & P-value \\
\hline Grade $\mathbf{0}$ No VPCs & 0 & 0 & $<0.05$ \\
Grade $\mathbf{1}<\mathbf{3 0}$ VPCs /hr & $39(65 \%)$ & $16(26.6 \%)$ & $<0.05$ \\
Grade $\mathbf{2}>\mathbf{3 0}$ VPCs /hr & $29(48.3 \%)$ & $8(13.3 \%)$ & 0 \\
Grade 3 Multiform VPCs & 0 & $9(15 \%)$ & $<0.05$ \\
Grade 4a Couplets & $28(46.6 \%)$ & $2(3.3 \%)$ & $<0.05$ \\
Grade 4b Salvos of V.T & $8(13.3 \%)$ & 0 & 0 \\
Grade 5R on T Phenomenon & 0 & 0
\end{tabular}

\subsection{Isolated Ventricular Ectopy}

In comparing both cardiac and normal groups with regard to ventricular ectopy, 27 (90\%) of cardiac patients developed ventricular ectopy on a khat-chewing day compared to only 13 (43.3\%) individuals developed the same on a khat-free day $(p<0.01)$ Figure 2. In contrast to $12(40 \%)$ individuals of normal group, developed isolated ventricular ectopy on a khat-chewing day, only $3(10 \%)$ developed the same on a khat-free day $(p<$ 0.01 ) as in Figure 3.

\subsection{Frequent Ventricular Ectopy}

21 (70\%) cardiac patients developed frequent ventricular ectopy on a khat-chewing day compared to only 7 (23.3\%) individuals developed the same on a khat-free day as in Figure 2. Whereas 8 (26.6\%) normal individuals developed frequent ventricular ectopy on a khat-chewing day, only $1(3.3 \%)$ individual developed the same on a khat-free day (Figure 3).

\subsection{Complex Ventricular Ectopic Beats and Couplets}

22 (73.3\%) cardiac patients developed ventricular couplets on a khat-chewing day in comparison to only 9 (30\%) cardiac patients on a khat-free day as in Figure 2. While 6 (20\%) normal individuals developed ventricular couplets on a khat-chewing day, none of them showed any ventricular couplets on a khat-free day (Figure 3).

\subsection{Non-Sustained Ventricular Tachycardia}

Non-sustained ventricular tachycardia was observed in 7 (23.3\%) cardiac patients on a khat-chewing day in comparison to 2 (6.6\%) individuals on a khat-free day as in Figure 2. But the normal individual group showed only 1 (3.3\%) individual developed non-sustained VT on a khat-chewing day compared to none on a khat-free day (Figure 3). The maximal episodes detected were 38 in one patient and the minimum were 2 episodes and the longest run was 12 beats.

\section{Discussion}

Khat contains several chemical harmful agents as mentioned above. Cathinone, Cathine, and Ephedrine are the major cardiovascular affecting drugs [2].

Cathinone, an Amphetamine and Cocaine-like substance, may act as sympathomimetic stimulants whose overdose may cause tachycardia, hypertension and increase the risk for myocardial infarction [9]. In addition, cocaine effects may also cause coronary vasospasm and cardiac arrhythmias.

Ephedrine increases the force of myocardial contraction and cardiac output. Furthermore, systolic and diastolic blood pressure is also increased; thus, increasing myocardial oxygen demand and inducing myocardial ischemia and cardiac arrhythmias. 


\subsection{Previous Studies}

Several previous studies such as Luqman and Danoski et al. [3] reported that hypertension is not observed among chewers and in the same line Mancioli and Marrinello stated that cases of angina or disorders of peripheral circulation have never been detracted. On the contrary, many modern studies deny the above mentioned observations and confidently prove that strong relationships occur between chewing khat and hypertension, myocardial infarction incidence [11] and other cardiovascular events and this goes hand by hand with the above mentioned effects of khat constituents.

\subsection{The Present Study}

We found that a good correlation occurs between khat chewing and increased incidence of arrhythmias. So, arrhythmias increased significantly on a khat-chewing day in comparison to a khat-free day among all population as in Figure 1 and Table 2 and, at the same time, in both cardiac patients and normal individuals separately, as in Figure 2 and Figure 3.

To the best of our knowledge, no previous investigators reported the effects of khat chewing on cardiac arrhythmia induction, particularly ventricular arrhythmias. Therefore, we think that the present study goes hand by hand with the previous reports in regard to khat chewing, associating with major cardiovascular risk factors.

\subsection{Electrophysiological Mechanism of Arrhythmias Induction by Khat Chewing}

The exact mechanisms by which khat chewing triggers or aggravates ectopic impulse generation remain speculative. So, a variety of hypothetical mechanism has been put forward.

- Khat causes a transient elevation of blood pressure, which may cause the stretching of myocytes. This has been incriminated for decreasing electrical threshold amplitude and, at the same time, the hemodynamic overload of the left ventricle (caused by the increased blood pressure) could directly trigger ectopic activity.

- Khat increases heart rate, blood pressure and myocardial contractility. All of them are major determinants of myocardial oxygen consumption and may enhance myocardial oxygen demand. Therefore, relative ischemia may occur and may induce cardiac arrhythmias.

- Sympathetic over activity: Khat mainly contains Cathinone, Choline and Ephedrine, which have sympathomimetic stimulating effects and may increase sympathetic outflow or prolong action of catacholamines which proved to have a great role in triggering arrhythmias.

- Many alkaloids and other substances contained in khat have not been fully studied yet. In addition, the role of insecticides may have an arrhythmogenic effect and this has to be proved by experimental studies.

\subsection{Measures for Stoppage of Khat Chewing:}

A full programme of intensive efforts and procedures must be applied for eradication of such habit in Yemen, includes applying multiple educational programmes for society. Restrict khat planting and increase taxes for khat marketing. And first of all, government decision for real eradication of such bad and harmful plant must be achieved.

\section{Conclusions}

1) The prevalence of ventricular arrhythmias was higher on khat-chewing days in comparison to khat-free days, among all population and in each of cardiac and normal individual groups separately.

2) This may indicate small dose of beta blocker for high risk khat chewers just before chewing khat, to control khat induced transient hypertension and to give protection against arrhythmia.

\section{References}

[1] Kalis, P. (1996) Catha edulis: A Plant that Has Amphetamine Effects. Pharmacy World and Science, 18, 69-73.

[2] Kite, G.C., Ismail, M., Simmonds, M.S. and Hoghton, P.I. (2003) Use of Doubly Protonated Molecules in the Analysis of Cathedulins in Crude Extract of Khat (Catha edulis) by Liquid Chromatography/Serial Mass Spectrometry. Rapid Communications in Mass Spectrometry, 17, 1553-1564. http://dx.doi.org/10.1002/rcm.1085

[3] Luqman, W. and Danowski, T.S. (1976) The Use of Khat (Catha edulis) in Yemen: Social and Medical Observations. 
Annals of Internal Medicine, 85, 246-249. http://dx.doi.org/10.7326/0003-4819-85-2-246

[4] Alem, A. and Shifre, A. (1997) Khat Induced Psychosis and Its Medico-Legal Implication: A Case Report. Ethiopian Medical Journal, 35, 137-139.

[5] Kalix, P. (1991) The Pharmacology of Psychoactive Alkaloids from Ephedra and Catha. Journal of Ethnopharmacology, 32, 201-208. http://dx.doi.org/10.1016/0378-8741(91)90119-x

[6] Maitai, C.K. and Dhadphile, M. (1988) Khat Induced Paranoid Psychosis. The British Journal of Psychiatry, $152,294$.

[7] Nielsen, J.N. (1985) Cathinone Affects Dopamine and 5-Hydroxytryptamine Neurosis in Vivo as Measured by Changes in Metabolits and Synthesis in Four Forebrain Regions in the Rat. Neuropharmacology, 24, 845-852. http://dx.doi.org/10.1016/0028-3908(85)90035-8

[8] Rothman, R.B., Vu, N., Partilla, J.S., Roth, B.L., Hufeisen, S.J., Compton-Tooth, B.A., Birkes, J., Young, R. and Glennon, R.A. (2003) In Vitro Characterization of Ephedrine-Related Steroisomers at Biogenic Amine Transporters and the Receptorome Reveals Selective Actions as Norepinephrine Transporter Substrates. Journal of Pharmacology and Experimental Therapeutics, 307, 138-145. http://dx.doi.org/10.1124/jpet.103.053975

[9] Halket, J.M., Karasu, Z. and Murray-Lyon, I.M. (1995) Plasma Cathinone Levels Following Chewing Khat Leaves (Catha edulis Forsk). Journal of Ethnopharmacology, 49, 111-113. http://dx.doi.org/10.1016/0378-8741(95)90038-1

[10] Banjaw, M.Y. and Schmidt, W.J. (2005) Behavioural Sensitization Following Repeated Intermittent Oral Administration of Catha edulis in Rats. Behavioural Brain Research, 156, 181-189. http://dx.doi.org/10.1016/j.bbr.2004.05.020

[11] Al-Mutarreb, A., Al-kibsi, M., Al-Adhi, B. and Broadley, K.J. (2002) Khat Chewing and Acute Myocardial Infarction. Heart, 87, 279-280. http://dx.doi.org/10.1136/heart.87.3.279

\section{Submit or recommend next manuscript to OALib Journal and we will provide best service for you:}

- Publication frequency: Monthly

- 9 subject areas of science, technology and medicine

- Fair and rigorous peer-review system

- Fast publication process

- Article promotion in various social networking sites (LinkedIn, Facebook, Twitter, etc.)

- Maximum dissemination of your research work

Submit Your Paper Online: $\underline{\text { Click Here to Submit }}$

Contact Us: service@oalib.com 